\section{THE PROPOSED TEACHING UNIVERSITY} FOR LONDON.

$W^{\mathrm{E}}$ printed last week the petition which has been presented to the Privy Council by the Association for Promoting a Teaching University in London. We have now before us the petition of University College and King's College, to which is appended a proposed draft charter for the University, under the name of the Albert University of London. If, as seems probable, the promoters have been well advised in claiming no less a surname than that of the Metropolitan district for which the University is to serve, the prefixed name of the late Prince Consort, to whom England is undoubtedly indebted for the encouragement his influence gave to educational and scientific work, is perhaps as good a way as could have been hit upon for avoiding confusion with the existing University. For the rest, the charter appears to be an adaptation to the circumstances of that granted to the Victoria University ; the principal differences beingthe place reserved for the Royal College of Physicians and Royal College of Surgeons in the University, which is one of complete equality with the governing bodies of the University Colleges themselves; the power conferred upon the legally recognized medical schools of London, as such, to claim, as of right, admittanse to the University, on equal terms with the Medical Faculties of University College and King's College ; an 1 the greater simplicity of the governing body. In the case of the Victoria University a complicated division of authority was resorted to, with the view of obviating mutual jealousies between the various cities and towns in which, in that case, the several Colleges were to be situated. The Senate proposed for the Albert University consists of three members chosen by the governing body of each College associated with the University; the College of Physicians and College of Surgeons being reckoned among associated Colleges, if willing to accept the position, but the twelve medical schools not being so reckoned; of four members representing the assembly of each Faculty, such assemblies being composed of the teaching staffs of all Colleges or medical schools admitted in respect of the Faculty; and of six representatives nominated by the Crown in the first instance, of whom three are eventually to be replaced by representatives of the graduates in Convocation.

Compared with this body, the composition of the Senate of Physicians and Surgeons proposed in the petition of the two Royal Colleges presents an even greater degree of simplicity. No provision is made for the representation of any other interest than that of the petitioners themselves; and the two Colleges divide the representation equally between their respective governing bodies. It is understood, however, that in the case of the College of Surgeons this proposal has not given satisfaction, even within the limits of the College ; and that some representation will be claimed for Fellows of the College other than those who constitute the Council which governs it.

From the point of view which is especially our own, the quarrel about degrees, and the interests of rival institutions, occupy a place secondary in importance to considerations affecting the promotion of knowledge and science, and only important in so far as they are concerned. If the proposal of the Royal Colleges is carried into effect, and a committee of eminent physicians and surgeons is intrusted with the power of examining for and giving medical degrees, there can be little doubt that the great building on the Thames Embankment, and the space behind it shortly to be covered with building, will speedily develop into a teaching institution, with provision for research; and thus knowledge will be increased, and science promoted, by the addition of one more to the number of efficient schools for special purposes which are now open in London. The promoters of the Albert University do not offer us any immediate addition of this nature to the resources which are now available. We have examined the draft charter with care, in order to detect, if possible, the traces of a design to check the foundation or perfecting of new institutions, in the interest of those already existing. But the promoters, we are bound to say, appear to have guarded against all objection, by following, in this respect, the charter of the Victoria University. The appeal which is given to the Privy Council, in case of the refusal of the University to admit a new College, is a satisfactory provision against the spirit of monopoly. In the absence of danger from this point of view, the Teaching University promises more than is offered by the Senate of Physicians and Surgeons, in the interests of science. The prospect of establishing, as a qualification for admission to the University, a general standard of efficiency for Colleges professing to do the work of scientific teaching, has greater attractions for us than that of the opening of a single new school of medical and surgical research. Moreover, by the institution of the Teaching University; we shall secure the first, without rendering it less probable that in time the second also may follow.

We notice that the right of admission offered to all the London medical schools, though absolute so far as the Medical Faculty is concerned, is, in regard to the Faculty of Science, made conditional on efficiency. This is as it should be. Probably some of the smaller hospitals will regard with equaminity the extinction of their pretensions to be recognized as efficient schools of science. Others will be incited to render themselves efficient. In both cases the result to science will be a pure gain. One matter of importance appears omitted in the programme of the Albert University: the position to be assigned within the University, if its admission is contemplated, to the Royal School of Mines and Normal College of Science. It would appear proper that this point should be further considered, if the project ever reaches a more definite stage.

Upon the matters in dispute between the University of London and the University Colleges we desire to maintain an attitude of impartiality. On the one hand, it is urged that the credit of a degree will not stand the strain consequent on the creation of a second degree-giving body in London; and that all the reform desirable, in the interests of education, is the introduction of a larger number of teachers on the governing $b$ dy of the existing University. On the other, stress is laid upon the importance, for educational purposes, of the independence of teachers from irresponsible external control, and upon the necessity of an organization of teaching for London more thorough than can be afforded by any constitution or reconstitution of an examining body. But whether 
the desired reforms are carried out by changing the constitution of the University of London, or by instituting a new University, two things appear in any case to be incontestable: that the open examinations conducted by the existing University shall continue to be conducted by an impartial authority; and that the Colleges shall be allowed to organize their work in the manner best suited to promote their own efficiency.

Sir Philip Magnus, in a letter which appeared in the Times on Thursday, appears to consider the dispute as one between the efficiency of "lectures" on the one hand, and of "reading" on the other; and he cites the now well-known dictum of Darwin, in favour of reading, and against lectures. But it would be to mis-read, in a strange manner, the lesson of Darwin's life, if from it were to be drawn a conclusion against the existence of Universities for teaching purposes, and in favour of examinations. If Darwin carried from Edinburgh a profound dislike to unintelligent lecturing, of the epideictic sort, he was at Cambridge known as "the man who walks with Henslow." In Sir W. Hamilton's famous analysis of the work of Universities, examination holds the first place only among no less than seven "exercises" by which study, in a teaching institution, can be promoted ; the others being "disputation, repetition, written composition, the practice of teaching, conversation with and interrogation of the learned, and social study." To these must be added, by the student of science, the practice of experiment under competent supervision. Some of these appear to us of more value than examinations, some of less ; but it is obvious that an institution which is solely concerned with examinations does not cover the whole ground of institutional aid to study ; and it is of no avail, as between one institution and another, to exalt the benefits of " reading," which is not peculiar to either. In conclusion, we trust all parties to the controversy will bear constantly in mind that degrees and examinations, lectures and colleges, are, after all, but means to an end. The end is the spread and advancement of knowledge, through educational methods and research.

\section{MANUAL OF BRITISH DISCOMYCETES.}

A Manual of the British Discomycetes. By William Phillips, F.L.S. 8 vo, 446 pages, 12 plates. International Scientific Series. (London: Kegan Paul, Trench, and Co., 1887.)

T $\mathrm{T}$ is by no means an uncommon misfortune to find that 1 text-books are not written by persons the most competent, or with the widest experience; hence the results are very far from satisfactory, and no one expresses much gratification. Now and then notable exceptions to this rather general rule may be discovered, to the delight of all who are interested in that special branch of science to which the book is devoted, and the great edification of the student. It is beyond our province to inquire why the most suitable men are so seldom engaged in the production of "manuals," or why the most skilful manipulator, with a few months' study and much " coaching," cannot compete successfully with the practical hand well steadied with a twenty years' experience. It will be enough to intimate that no one acquainted with British Cryptogamic botany would for a moment hesitate to pronounce that the most suitable person to undertake a manual of the Discomycetes would be Mr. W. Phillips, of Shrewsbury, if practical knowledge, and persistent investigation, extending over at least two decades of years, are to be accepted as qualifications.

With these preliminary observations it will be at once evident that, in general terms, and as a whole, we feel bound to give this little volume our heartiest commendation; and if, in the course of our remarks, we indicate any weak places, it will be with the desire to act with the tenderness of a friend, and to point out how, in our conception, an admirable manual may be rendered more perfect or more useful.

No apology is needed for restricting a book like the present to a small controllable group of some 600 species, especially when the limits are so well defined that a student may devote himself exclusively to it, with advantage to himself, without any special acquaintance with outside groups. It is generally admitted that the entire British Fungi, with its thousands of described species, is become too unwieldy and extensive for any ordinary individual, not content to become a slave to his subject and a martyr to science. The Discomycetes present an admirable group, capable of isolated study; and for this purpose a careful and trustworthy manual, at a moderate price, is now ready at the student's hands.

"The subject of classification," the author says in his preface, "will not fail to awaken some controversy." "To adhere as closely as possible to the long-accepted Friesian system has been the practice of English authors, but this has been carried a little too far, owing to our 'insular prejudices,' and the time has come when a new departure must be made." We are prepared to accept this paragraph-exclusive of "insular prejudices," which we cannot admit-and with it the "new departure." To our mind this is a most moderate concession, and we doubt not that, if controversy there should be, its direction will be in favour of far greater innovation than Mr. Phillips or ourselves would approve. The details of the new arrangement must be subjected to closer examination and the test of experience, but at present we see no reason to take exception to them. We have long been of opinion that some such modification of the old classification was desirable.

There is, nevertheless, one point on which we have always uttered a protest, and repeat it again, since in two or three instances in the present volume the error has been committed. We allude to the addition to, or alteration of, a generic description, and the appending of the original author's name, with the word "amended" after it. We protest against amended genera, be cause they are nobody's genera ; they are not the genera of the original author, but a "thing of shreds and patches." A genus should not be altered or amended, in order to fit any subsequent species which a later author may desire to incorporate. He should keep the new species outside, and accommodate it in other ways, rather than modify or "tinker" the work of a predecessor, and assume the change to be an "amendment," whereas it may be something very different, and probably would be to the old author himself, if he could be resuscitated to gaze on the freaks of his successors.

As for the number of species described in this volume, 